Michele Masnaghetti

is strategic services director and

Luke Ditchburn is analytic consultant at Epsilon, a global marketing company that operates the UK's largest co-operative database, the Abacus Alliance. Launched in 1998, the Alliance has over 500 retailers, publishers and charities in membership supplying data on 18 million UK households covering 576 million transactions and $£ 20$ bn of spending. By using multi-source data on UK consumers, members of the Alliance are able to achieve higher marketing return on investment when recruiting new customers, as well as gaining deeper insights into their own buyers' behaviour.

Keywords: home shopping, direct marketing, direct mail, customer insight, black friday, cyber monday

\section{Transactional database co-operative}

\section{Unseasonally warm Autumn}

Epsilon Abacus, 67 Broad Street, Teddington Middlesex, TW11 8QZ, UK

Tel: +44 (0)2089438036

E-mail: mmasnaghetti@epsilon.com

\title{
Business Intelligence
}

\section{Abacus Annual Trends Report 2015}

\author{
Michele Masnaghetti and Luke Ditchburn \\ Received (in revised form): 23rd July 2015
}

\begin{abstract}
By pooling transactional data from home shopping businesses in the United Kingdom, Epsilon Abacus is able to gain an insight into underlying trends across the sector. For the fifth year in a row, the report shows overall year-on-year growth in the market with consumer spend up 12.0 per cent year on year in 2014. Growth was particularly strong in November (+14.3 per cent) possibly because of the growing importance of Black Friday and Cyber Monday in the UK market.

Journal of Direct, Data and Digital Marketing Practice (2015) 17, 36-42. doi:10.1057/dddmp.2015.35
\end{abstract}

\section{Background}

The Abacus Alliance is the United Kingdom's largest transactional database co-operative, built on the shared customer information of multi-channel retail members in the United Kingdom. Over 500 retailers, publishers and charities contribute to the database, which covers 18 million households comprising 26 million individuals, with over 500 million transactions accounting for $£ 20+$ bn in expenditures. The Abacus Alliance is part of Epsilon, a global marketing company operating in 70 offices worldwide. Each year, the Epsilon Abacus Annual Trends Report reviews consumer spending patterns in the home shopping market based on actively trading companies who have provided upto-date transactional information. Data on direct mail volumes is sourced from Ebiquity, which operates a sampling panel, and overlaid on the transactional data. Trends are presented using indices to the 2-year monthly average. This article looks at the key findings from this review.

\section{Home shopping overview}

Sales in the home shopping sector grew by 12.0 per cent year-on-year (YOY) in 2014, building on 10.2 per cent growth in 2013 and 8.9 per cent growth in 2012, indicating the strength of this sector. There was a strong start to the year, with Quarter 1 growing by 14.1 per cent and Quarter 2 by 14.8 per cent, although unusually warm weather in Autumn slowed clothing sales in September and October to give overall growth in Quarter 3 of 9.3 per cent. There was a strong pick-up in November, which allowed sales in Quarter 4 to rebound with a rise of 10.5 per cent (see Figure 1). 


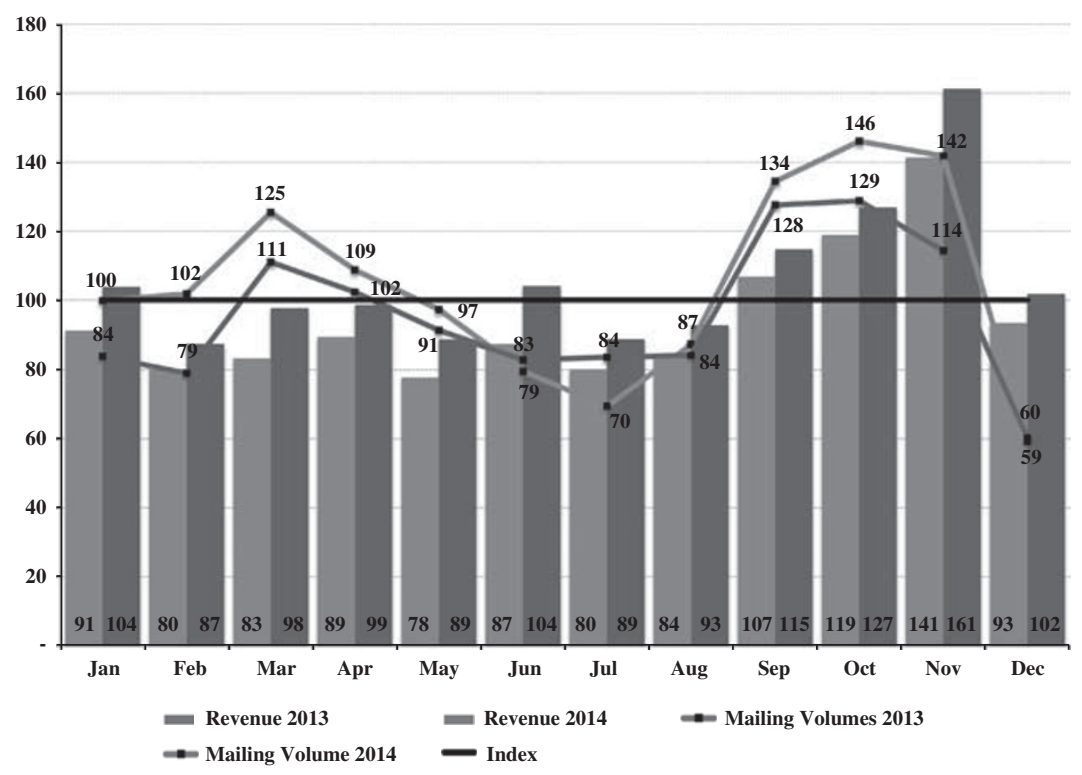

Figure 1: Revenue and mailing volumes 2014 versus 2013

\section{Seasonal restructuring}

\section{Drop in direct mail}

\section{Average order value rises}

Aggressive sales on Cyber Monday and Black Friday - pre-Christmas discount events that have been transferred to the United Kingdom from the United States - seem to have had a significant impact on sales in November. Retailers are increasingly seeing a restructuring of the traditional seasonal shopping patterns at this time of year, with November now being the peak trading month.

Direct mail volumes showed a decline of 8.1 per cent YOY, following an increase of 7.0 per cent in 2013. Quarter 1 saw a -16.2 per cent drop in mailings compared to 2013, while Quarter 2 was down only -3.2 per cent. A slight increase of 1.5 per cent in Quarter 3 was followed by a further drop of -12.6 per cent in Quarter 4. This shift away from direct mail reflects increasing promotional activity in digital channels, such as email and online advertising. As Lara Bonney, UK country director, Epsilon Abacus, notes, 'Consumers today want to browse and buy through channels that suit them - 2014 success came to businesses that provide a consistent experience for the consumer across the different touch points. Mail volumes declined overall in 2014 YOY, yet revenues grew. It indicates that, while catalogues are still a key sales driver, home shopping businesses are becoming more adept at maximising other channels'.

Average order value (AOV) rose marginally during the year to reach $£ 49.58$, compared with $£ 49.04$ in 2013 (see Figure 2). January saw a substantial increase of 2.6 per cent in AOV and maintained a higher level compared with the previous year until July. While August AOV was similar to 2013, September and October fell back by -2.8 per cent and -3.2 per cent, respectively, driven by lower clothing sales as a result of warmer than usual weather. As the modest rise in AOV shows, growth in home shopping is being fuelled by a combination of new customers coming to the marketplace and existing customers placing more orders. 


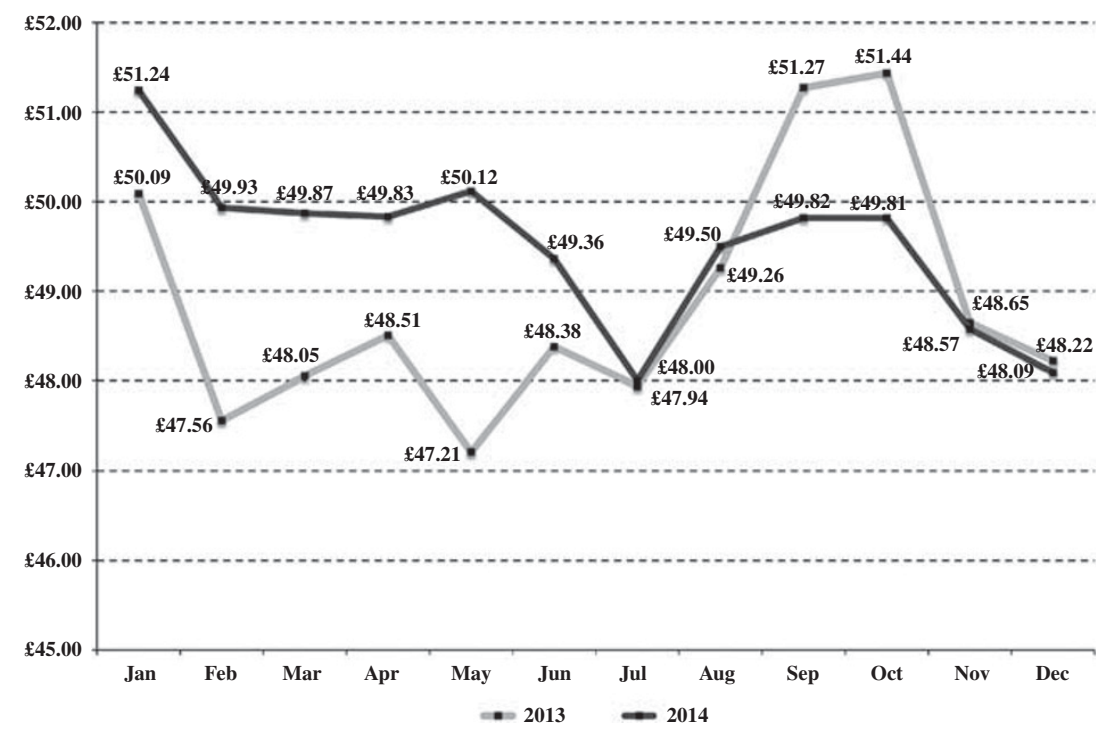

Figure 2: Average order value year-on-year 2014 versus 2013

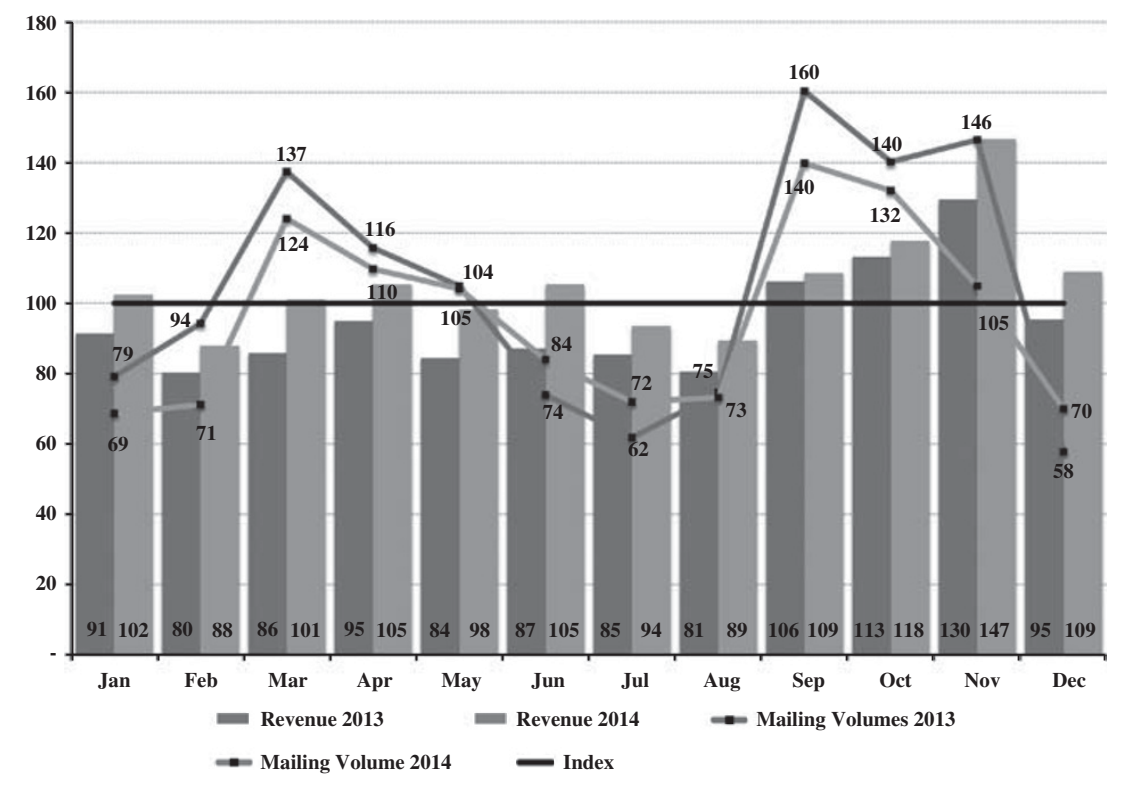

Figure 3: Clothing revenue and mailing volumes 2014 versus 2013

Sales growth and seasonality

\section{Clothing sector overview}

Clothing sales have risen for 5 years in a row, culminating in an 11.6 per cent increase in 2014 (see Figure 3). This makes it one of the most successful sectors in home shopping. While growth was strong across the year, September and October both saw weaker sales increases ( 2.3 per cent and 4.1 per cent, respectively). November, which is traditionally the biggest month for clothing sales, had a YOY increase of 13.3 per cent 


\section{Discounting not sustainable}

Flat sales in 2014

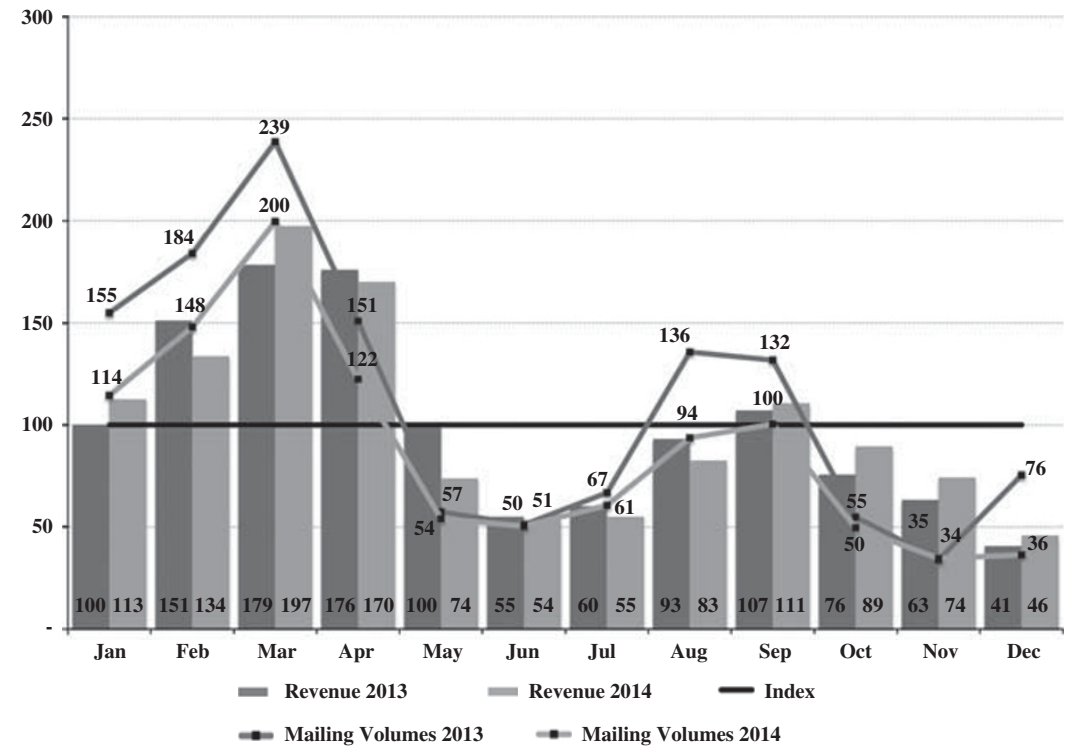

Figure 4: Gardening revenue and mailing volumes 2014 versus 2013

compared with 2013. Average order values were slightly down, however, at -0.5 per cent, reflecting downward price pressure and competition. Clothing retailers sent 7.5 per cent less direct mail in 2014 compared with 2013, with significant falls during February ( -24.5 per cent) and November (-28.4 per cent), although there were rises in June (13.7 per cent), July (16.4 per cent) and December (21.2 per cent) compared with the previous year.

Georgie Coleridge Cole, founder of SheerLuxe.com, notes, 'Moving away from discounting has been tough for retailers - a brave few achieved it although many are still in deep. As a publisher, we're faced with brands wanting demonstrative ROI which, when most of your readers view your content via a phone and you're at the inspiration phase of a decision process, is difficult to prove without a really compelling call to action. However, we understand that it's not sustainable. If your product is good and can't be found elsewhere, people will still buy it'.

\section{Gardening sector overview}

The gardening sector was virtually flat during 2014 compared with 2013, with a marginal decline in revenue of -0.2 per cent. The middle of the year saw a significant drop in sales - -10.1 per cent in Quarter 2 and -4.7 per cent in Quarter 3 - undoubtedly as a result of weather factors (see Figure 4). This was offset by growth of 3.2 per cent in Quarter 1 and a significant upswing of 16.6 per cent in Quarter 4. While sales were stable, average order values rose by 2.0 per cent. Gardening retailers invested significantly less in direct mail, with volumes down YOY by 20.3 per cent. 
Strong 4-year growth

\section{Quarter 4 still dominates}

Upscaling during sales

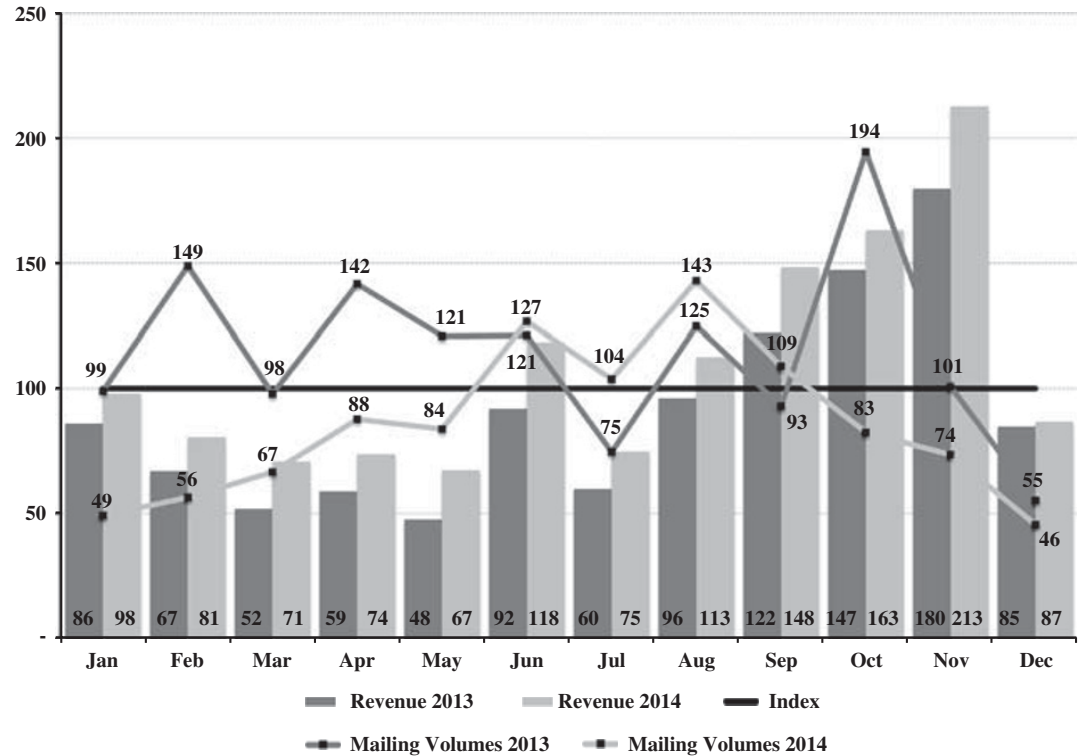

Figure 5: Generalist retail revenue and mailing volumes 2014 versus 2013

\section{Generalist retail overview}

Sales figures for generalist retailers have grown 19.6 per cent in 2014, continuing the growth trend started 4 years ago. There was growth across all months, with May showing a particular spike of 41.5 per cent YOY, although December sales grew by just 2.2 per cent, probably as a result of consumers bringing forward Christmas purchases in response to retailers' offers in November. Average order value grew by 3.1 per cent. Generalist retailers held back direct mail volumes significantly YOY, except for increases during June, July, August and September (see Figure 5).

\section{Gifts, gadgets and entertainment overview}

There was modest growth of 0.3 per cent during 2014 in this sector with tough trading conditions during the first half, which saw revenue decline in Quarter 1 by -2.2 per cent and in Quarter 2 by -12.4 per cent. During May, sales fell by nearly 25 per cent compared with the same month in 2013. There was a pick-up during Quarter 3 of 3.2 per cent and in Quarter 4 of 7.4 per cent. As the last 3 months of the year account for nearly 40 per cent of annual revenues, the growth in this period offset the weak start to the year. November was particularly strong in 2014 with YOY growth of 10.7 per cent - this is the month in which Cyber Monday and Black Friday take place. Mailing volumes were relatively stable, at just -3.1 per cent YOY, although July saw a spike of 43.2 per cent more volume than in the same month the previous year. (Figure 6)

\section{Home interiors and household goods overview}

There was good growth of 15.1 per cent YOY in this sector, with a strong start in Quarter 1, up by 27.2 per cent in January alone with an increased 


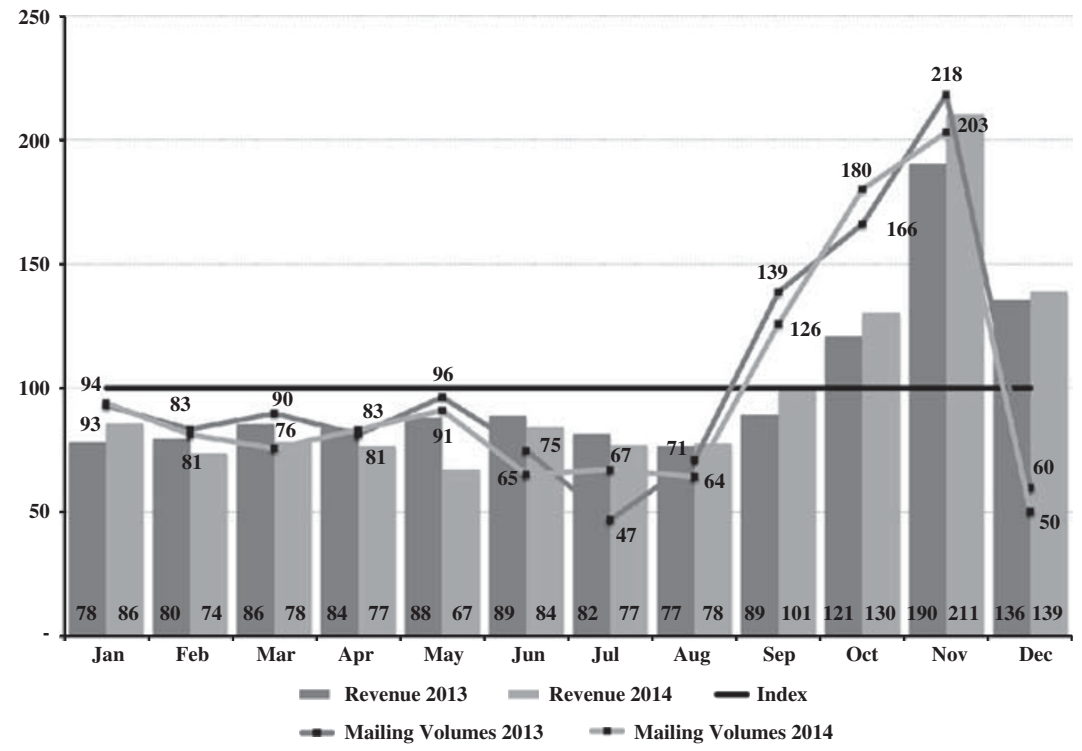

Figure 6: Gifts, gadgets and entertainment revenue and mailing volumes 2014 versus 2013

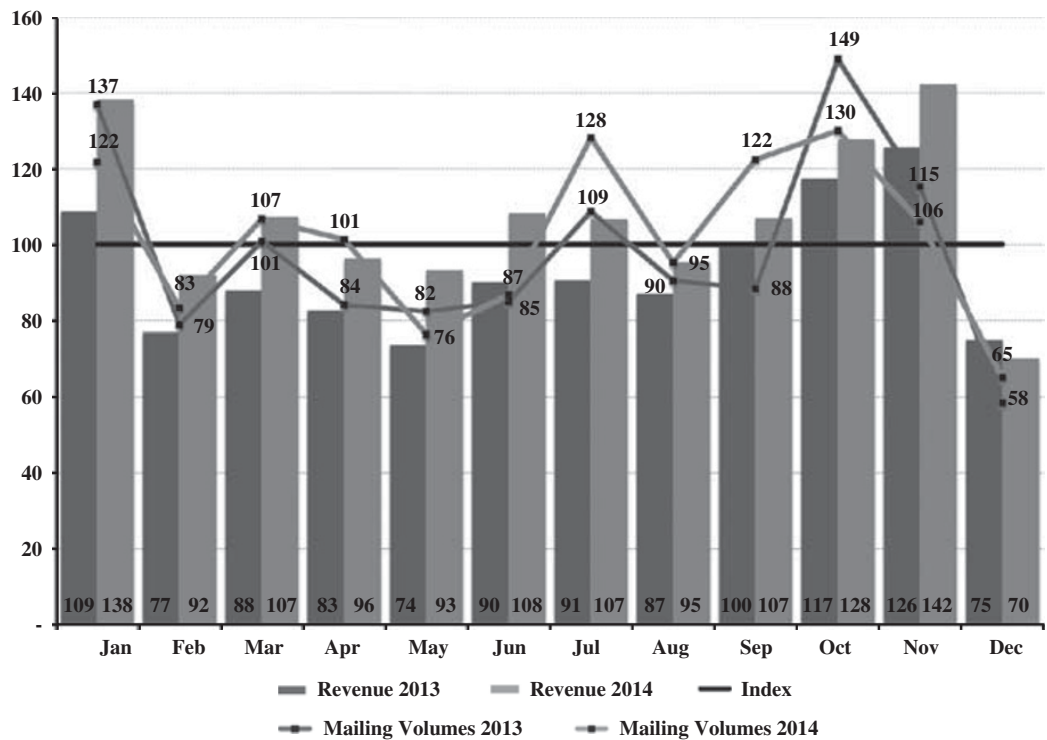

Figure 7: Home interiors and household goods revenue and mailing volumes 2014 versus 2013

average order value of 12.0 per cent. This may reflect upscaling as consumers bought higher-value items during the January sales. Growth continued in Quarter 2 at 20.8 per cent YOY, while Quarter 3 extended the trend with an increase of 11.2 per cent and Quarter 4 added 7.0 per cent YOY. Sales volumes rose, while average order values softened slightly $(-0.4$ per cent). This sector also saw a rise in direct mail volumes with 3.8 per cent more mailing pieces being circulated than during 2013 . (Figure 7) 
Direct mail driving sales online and in-store
'Customers can research products, find the lowest price and quickest delivery terms more easily than ever before', says Katy Ingram, head of marketing, Feather and Black. 'Retailers are responding to the huge changes that digital technology is having on their traditional bricks and mortar outlets. In 2014, we saw strong growth online driven by increased investment in paid and natural search. We also increased our investment in cold list mailings on the back of positive results in the prior year. Direct mail continues to be an important part of the marketing mix for us, driving both retail and online sales'. 